\title{
Supercontinuum generation in photonic crystal fibers infiltrated with tetrachloroethylene
}

\author{
Hieu Van Le $e^{1}$ Van Thuy Hoang ${ }^{2,3,4} \cdot$ Hue Thi Nguyen ${ }^{3,4}$. Van Cao Long ${ }^{5}$. \\ Ryszard Buczynski ${ }^{3,4} \cdot$ Rafał Kasztelanic ${ }^{3,4}$ (D)
}

Received: 20 May 2020 / Accepted: 7 March 2021 / Published online: 29 March 2021

(c) The Author(s) 2021

\begin{abstract}
This study proposes a photonic crystal fiber made of fused silica glass, with the core infiltrated with tetrachloroethylene $\left(\mathrm{C}_{2} \mathrm{Cl}_{4}\right)$ as a new source of supercontinuum (SC) spectrum. We studied numerically the guiding properties of the several different fiber structures in terms of characteristic dispersion, mode area, and attenuation of the fundamental mode. Based on the results, the structural geometries of three $\mathrm{C}_{2} \mathrm{Cl}_{4}$-core photonic crystal fibers were optimized in order to support the broadband SC generations. The first fiber structure with lattice constant $1.5 \mu \mathrm{m}$ and filling factor 0.4 operates in all-normal dispersion. The SC with a broadened spectral bandwidth of $0.8-2 \mu \mathrm{m}$ is generated by a pump pulse with a central wavelength of $1.56 \mu \mathrm{m}, 90 \mathrm{fs}$ duration and energy of $1.5 \mathrm{~nJ}$. The second proposed structure, with lattice constant $4.0 \mu \mathrm{m}$ and filling factor 0.45 , performs an anomalous dispersion for wavelengths longer than $1.55 \mu \mathrm{m}$. With the same pump pulse as the first fiber, we obtained the coherence SC spectrum in an anomalous dispersion range with wavelength range from 1 to $2 \mu \mathrm{m}$. Meanwhile, the third selected fiber (lattice constant $1.5 \mu \mathrm{m}$, filling factor 0.55 ) has two zero dispersion wavelengths at $1.04 \mu \mathrm{m}$ and $1.82 \mu \mathrm{m}$. The octavespanning of the SC spectrum formed in this fiber was achieved in the wavelength range of $0.7-2.4 \mu \mathrm{m}$ with an input pulse whose optical properties are $1.03 \mu \mathrm{m}$ wavelength, $120 \mathrm{fs}$ duration and energy of $2 \mathrm{~nJ}$. Those fibers would be good candidates for all-fiber SC sources as cost-effective alternatives to glass core fibers.
\end{abstract}

Keywords Photonic crystal fibers · Supercontinuum generation · Dispersion · Tetrachloroethylene $\cdot$ Nonlinear optics

Rafał Kasztelanic

kasztel@igf.fuw.edu.pl

1 Institute of Research and Development, Duy Tan University, Da Nang 550000, Vietnam

2 Department of Physics, Vinh University, Nghe An Province, 182 Le Duan, Vinh City, Vietnam

3 Faculty of Physics, University of Warsaw, Pasteura 5, 02-093 Warsaw, Poland

4 Lukasiewicz Research Network - Institute of Microelectronic and Photonics, Aleja Lotników 32/46, 02-668 Warsaw, Poland

5 Institute of Physics, University of Zielona Góra, Prof. Szafrana 4a, 65-516 Zielona Gora, Poland 


\section{Introduction}

Supercontinuum (SC) lasers, i.e. light sources exhibiting an ultra-broad band of frequencies and good quality beam (Liu et al. 2019), have been a subject of intense research over the past decade. Their applications cover many areas such as spectroscopy, frequency metrology, biomedicine, and optical coherence tomography (Holzwarth et al. 2000; Udem et al. 2002; Tu and Boppart 2013; Sharma et al. 2008).

A number of techniques have been proposed for the generation of SC in which the high nonlinearities and low dispersion profiles play important roles. A typical approach for this purpose is utilizing photonic crystal fibers (PCFs) made of silica or highly nonlinear soft glasses (Dudley et al. 2006; Dai et al. 2018; Nguyen et al. 2019; Klimczak et al. 2019; Buczynski et al. 2010). Silica fibers work efficiently for SC generations from the visible to the near-infrared (IR) range, but not for the mid-IR range due to their limited transmission bandwidth (Dudley et al. 2006). Moreover, silica shows relatively low nonlinearity, so silica fibers require input pulses with high peak power for broad SC spectra. Although the nonlinear coefficient of the silica-core PCFs can be enhanced by reducing its effective core area, this approach will lead to difficulties in light coupling. A second common approach is to use highly nonlinear soft glass materials such as chalcogenide (Dai et al. 2018), tellurite (Nguyen et al. 2019; Klimczak et al. 2019) or lead-bismuth-gallate glass (Buczynski et al. 2010). However, these fibers are incompatible with silica for fusion splicing, limited in power handling, and usually require complex pump systems. Other disadvantages of these glasses include the following. First, they might be mechanically weak. Secondly, more complex fiber structures may be difficult to fabricate, and may require more thermal processes which can result in crystallization.

An alternative solution is liquid-infiltrated optical fibers, as demonstrated in previous research (Zhang et al. 2006; Fanjoux et al. 2017; Van et al. 2018a; Maji and Chaudhuri 2014; Pniewski et al. 2016; Ding et al. 2018; Lanh et al. 2019; Van et al. 2020). Unlike silica, nonlinear liquids show high nonlinearity that is comparable with the nonlinear soft glasses (Kedenburg et al. 2014). Some of them, e.g. carbon disulfide $\left(\mathrm{CS}_{2}\right)$, carbon tetrachloride $\left(\mathrm{CCl}_{4}\right)$ are highly transparent in the near-IR range (Churin et al. 2013; Kedenburg et al. 2012). In addition, liquids are able to be mixed to optimize their optical properties, e.g. linear refractive index for practical applications (Wohlfarth 2008). Another advantage of using liquid core PCFs is that the generated SC spectra can be controlled by the modification of temperature or pressure since it is possible to alter the PCFs' dispersion properties via these factors (Van et al. 2018b; Du et al. 2004). Therefore, the infiltration of PCFs with liquids adds an extra degree of freedom for broadening applications in potential fields (Ebnali-Heidari et al. 2012), especially, with use of mid-IR SC laser sources in medical diagnostics (Chemnit et al. 2018), biomedical technologies (Guo et al. 2004) and remote sensing (Ambrico et al. 2000).

Up to date, most of the experimental results of liquid-core fibers SC generations are focused on the use of step-index liquid-core optical fibers since they are straight forward and convenient to fill micro-capillaries with liquids, as an equivalent of a step-index optical fiber. However, this approach lacks flexibility in designing the dispersion and modal properties of the fibers (Churin et al. 2013). Recently, use of liquid-filled PCFs has been received more attention because it overcomes the disadvantages of liquids capillary approach. The obtained results indicated that it is possible to shift the ZDW and match it with a pump wavelength of the high-power commercial laser, as well as obtaining allnormal and flat dispersion regime in the expected spectra (Van et al. 2018a; Maji and 
Chaudhuri 2014; Ding et al. 2018). Due to the higher nonlinear refractive index of selected liquids (Ding et al. 2018; Kedenburg et al. 2014), it is possible to achieve the broadband, coherent SC spectrum either in a few centimeters long liquid-core fiber sample, or with a lower peak power (Van et al. 2020).

Most of the works on SC generation considered with carbon disulfide $\left(\mathrm{CS}_{2}\right)$, nitrobenzene $\left(\mathrm{C}_{6} \mathrm{H}_{5} \mathrm{NO}_{2}\right)$, toluene $\left(\mathrm{C}_{7} \mathrm{H}_{8}\right)$, carbon tetrachloride $\left(\mathrm{CCl}_{4}\right)$ or chloroform $\left(\mathrm{CHCl}_{3}\right)$ (Ding et al. 2018; Lanh et al. 2019; Van et al. 2020; Churin et al. 2013; Hoang et al. 2019, 2018). Although, $\mathrm{CS}_{2}$ has a high nonlinear refractive index $n_{2}=220 \times 10^{-20} \mathrm{~m}^{2} / \mathrm{W}$ at the wavelength of $1030 \mathrm{~nm}$ (Kedenburg et al. 2014), 100 times higher than for fused silica $n_{2}=2.19 \times 10^{-20} \mathrm{~m}^{2} / \mathrm{W}$ (Kabaciński et al. 2019) and are transparent in the visible to near-IR $(0.5-2.2 \mu \mathrm{m})$ range (Churin et al. 2013), it is also a highly toxic, carcinogenic and explosive (Challenor 2002). $\mathrm{C}_{6} \mathrm{H}_{5} \mathrm{NO}_{2}$ and $\mathrm{C}_{7} \mathrm{H}_{8}$ are relatively low transparent in the near-IR range (Zhang et al. 2006; Hoang et al. 2018), resulting in a reduction of spectral broadening in the PCFs (Raei et al. 2018). Meanwhile, the advantage of $\mathrm{CHCl}_{3}$ is its moderate toxicity when compared to $\mathrm{CS}_{2}$ and $\mathrm{C}_{7} \mathrm{H}_{8}$. The upper limit of the acceptable concentration of $\mathrm{CHCl}_{3}$ in air is $249 \mathrm{mg} \mathrm{m}^{-3}$ (IPCS 1994), while those limits are $188 \mathrm{mg} \mathrm{m}^{-3}$ and $31 \mathrm{mg} \mathrm{m}^{-3}$ for $\mathrm{C}_{7} \mathrm{H}_{8}, \mathrm{CS}_{2}$, respectively (Van et al. 2017). Its linear refractive index is lower than silica (Lanh et al. 2019). Therefore, total reflection mechanism cannot be achieved in PCFs. As a consequence, $\mathrm{CHCl}_{3}$ was not taken in consideration. Among those liquids, $\mathrm{CCl}_{4}$ is a better choice because of the moderate toxic property and highly transparent in the near-IR range (Kedenburg et al. 2012). However, for $\mathrm{CCl}_{4}$, the linear refractive index is similar to that of silica which leads to the low index contrast between the core and cladding and then results in the decrease of nonlinear coefficient (Ding et al. 2018).

In this paper, we numerically study on PCFs made of fused silica, having core infiltrated with tetrachloroethylene $\left(\mathrm{C}_{2} \mathrm{Cl}_{4}\right)$ as a propagating medium for $\mathrm{SC}$ generations. We have selected $\mathrm{C}_{2} \mathrm{Cl}_{4}$ because it has high nonlinear refractive index $n_{2}=16.75 \times 10^{-20} \mathrm{~m}^{2} / \mathrm{W}$ at $\lambda=1.55 \mu \mathrm{m}$ (Chemnit et al. 2018) (seven times higher than for fused silica $n_{2}=2.19 \times 10^{-20}$ $\mathrm{m}^{2} / \mathrm{W}$ (Kedenburg et al. 2014). In particular, $\mathrm{C}_{2} \mathrm{Cl}_{4}$ provides a super-wide transparent from the visible to mid-IR $(0.5-3.39 \mu \mathrm{m})$ (Takahashi et al. 1985). In addition, the upper limit of the acceptable concentration of $\mathrm{C}_{2} \mathrm{Cl}_{4}$ in air is $345 \mathrm{mg} \mathrm{m}^{-3}$ (DHHS 1993). $\mathrm{C}_{2} \mathrm{Cl}_{4}$ is then less toxic when compared to $\mathrm{CHCl}_{3}, \mathrm{C}_{7} \mathrm{H}_{8}$, and $\mathrm{CS}_{2}$ which is extremely important for practical applications. In our work, dispersion properties were optimized by modifying geometrical parameters of PCF, i.e. lattice constant and filling factor in order to obtain the dispersion flatness and location of ZDW in the analyzed wavelength range. For those optimum fiber structures, we utilized the generalized nonlinear Schrödinger equation (GNLSE) to demonstrate SC generations. The advantages of the selected PCFs would also be discussed.

\section{Numerical modeling of the PCF}

The cross-section of the geometrical structure of the modeled PCF is shown in Fig. 1. We assumed that the cladding of the fiber is made of fused silica glass and consists of eight rings of air holes arranged in regular hexagonal lattice defined by the lattice pitch $\Lambda$ and air holes diameter $d$. The linear filling factor of the cladding is defined as $f=d / \Lambda$ and a constant filling factor is used for all rings to simplify future fiber development. The diameter of the central air hole has to be large enough and fulfill the relation: $D c=2 \Lambda-1.2 \mathrm{~d}$, to ensure the technical feasibility of the considered structures during the fabrication process. During 

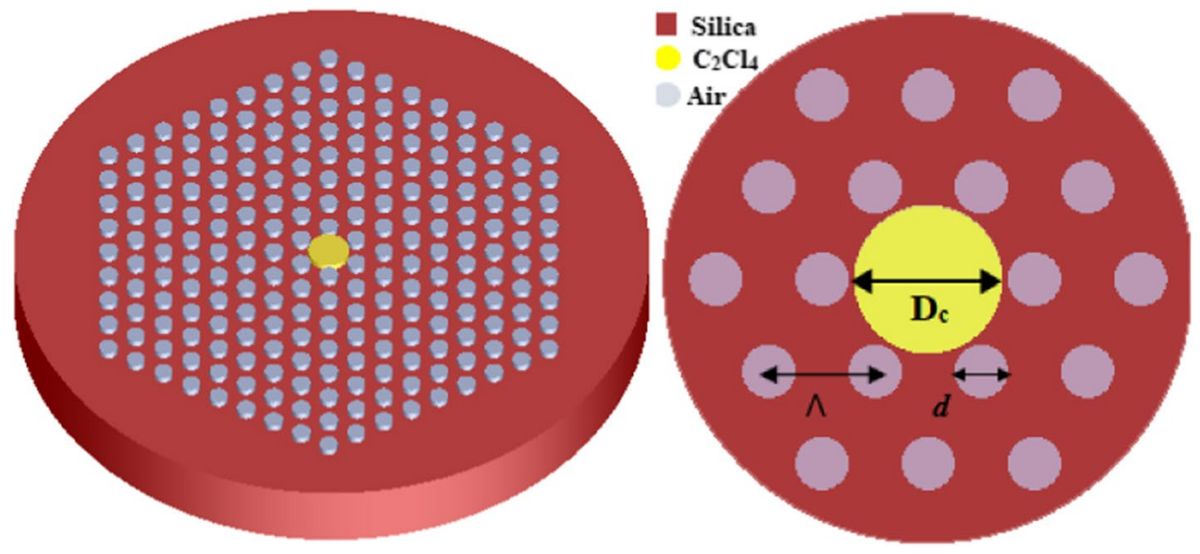

Fig. 1 Schematic of the modeled PCF structure, where Dc is the diameter of the liquid-filled core

numerical simulations process, the diameters of cladding holes increase with the growth of the filling factors and lattice pitches, while the core diameters decrease.

We assumed that the central hole is filled with $\mathrm{C}_{2} \mathrm{Cl}_{4}$. The characteristics of the real and imaginary parts of the refractive index of $\mathrm{C}_{2} \mathrm{Cl}_{4}$ showed in Fig. 2 . The refractive index characteristics modeled obeying Sellmeier equation and given by the formula:

$$
n(\lambda)=\sqrt{A_{1}+\frac{B_{1} \lambda^{2}}{\lambda^{2}-C_{1}}+\frac{B_{2} \lambda^{2}}{\lambda^{2}-C_{2}}+\frac{B_{3} \lambda^{2}}{\lambda^{2}-C_{3}}}
$$

where $B_{i}$ and $C_{i}$ are Sellmeier coefficients and $\lambda$ is the wavelength in $\mu \mathrm{m}$. The Sellmeier's coefficients for fused silica and $\mathrm{C}_{2} \mathrm{Cl}_{4}$ are presented in Table 1 .

The numerical analysis was carried out with the use of Lumerical Mode Solution software (Mode Solution 2020). The perfectly matched layer is the boundary condition used for the analysis of the PCF which makes no reflection at the boundary and reduces the loss.

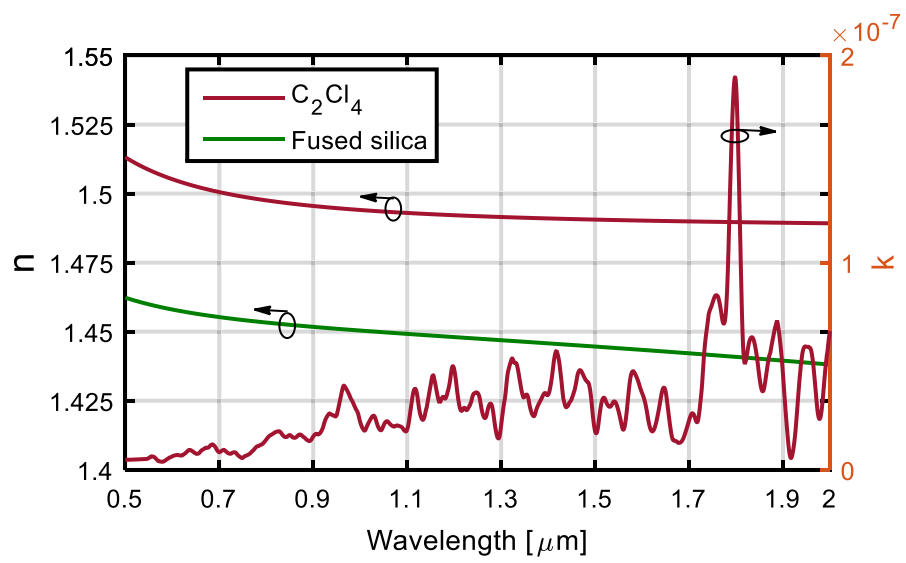

Fig. 2 Real part (n) and imaginary part (k) of the refractive index of $\mathrm{C}_{2} \mathrm{Cl}_{4}$ for the temperature of $20{ }^{\circ} \mathrm{C}$ (Chemnit et al. 2018). The green line denotes $n$ of fused silica 
Table 1 Sellmeier's coefficients for the fiber refractive index (Tan 1998; Chemnit et al. 2018)

\begin{tabular}{lll}
\hline Coefficient & Fused silica & Tetrachloroethylene \\
\hline$A_{1}$ & 1 & 1 \\
$B_{1}$ & 0.6694226 & 1.21453712 \\
$B_{2}$ & 0.4345839 & 0.03501419 \\
$B_{3}$ & 0.8716947 & 0 \\
$C_{1}\left(\mu \mathrm{m}^{2}\right)$ & 0.0044801 & 0.01456 \\
$C_{2}\left(\mu \mathrm{m}^{2}\right)$ & 0.013285 & 123.1074 \\
$C_{3}\left(\mu \mathrm{m}^{2}\right)$ & 95.341482 & 0 \\
\hline
\end{tabular}

In addition, conformal meshing was applied on all material interfaces to reduce meshing errors and increase the numerical accuracy of the simulations.

\section{Modeling modal and dispersion properties of the PCF}

Preliminary numerical simulations were conducted for the PCF having $\Lambda$ changing from 1.0 to $4.5 \mu \mathrm{m}$ with a step of $0.5 \mu \mathrm{m}$ and $f$ changing from 0.3 to 0.8 with a step of 0.05 . A number of simulations were carried out to observe the flatness of dispersion and the ZDW shift. Each simulation was done for wavelengths in the range of $0.5 \mu \mathrm{m}$ to $2.0 \mu \mathrm{m}$. Figure 3 a shows the maximum dispersion of the fundamental mode for various $\Lambda$ and $f$. For the case of the PCF with $\Lambda$ is greater than or equal to $2.0 \mu \mathrm{m}$, the maximum dispersion is greater than zero that means we got both normal and anomalous dispersion. In this case, for a given $\Lambda$ value, the maximum dispersion will increase with increasing $f$. Meanwhile, for a given $f$, the maximum dispersion values will decrease when we increase $\Lambda$. The example dispersion characteristic for this region is shown in Fig. 3b. In the rest cases, the dispersion takes values only in the normal dispersion regime or in both normal and anomalous dispersion regimes. Figure $3 \mathrm{c}$ shows an example of the dispersion characteristic of the
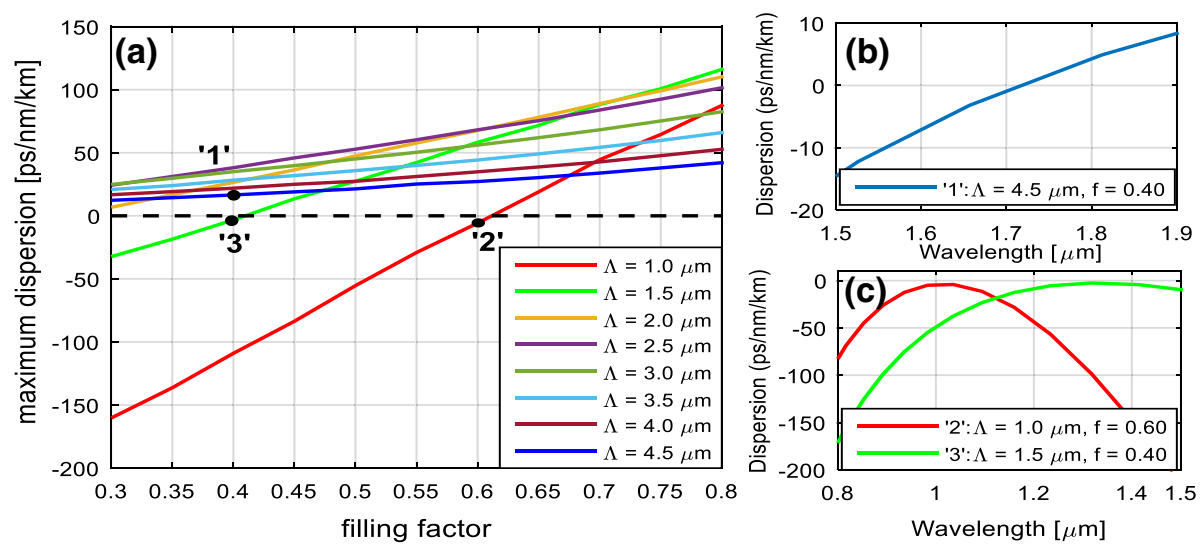

Fig. 3 Dispersions characteristics: a the maximum dispersion of the fundamental mode for various lattices pitch $\Lambda$ and filling factors $f$ in the considered region of wavelength from 0.5 to $2 \mu \mathrm{m}$, b PCF with both normal and anomalous dispersion, $\mathbf{c}$ PCF's with all normal dispersion 


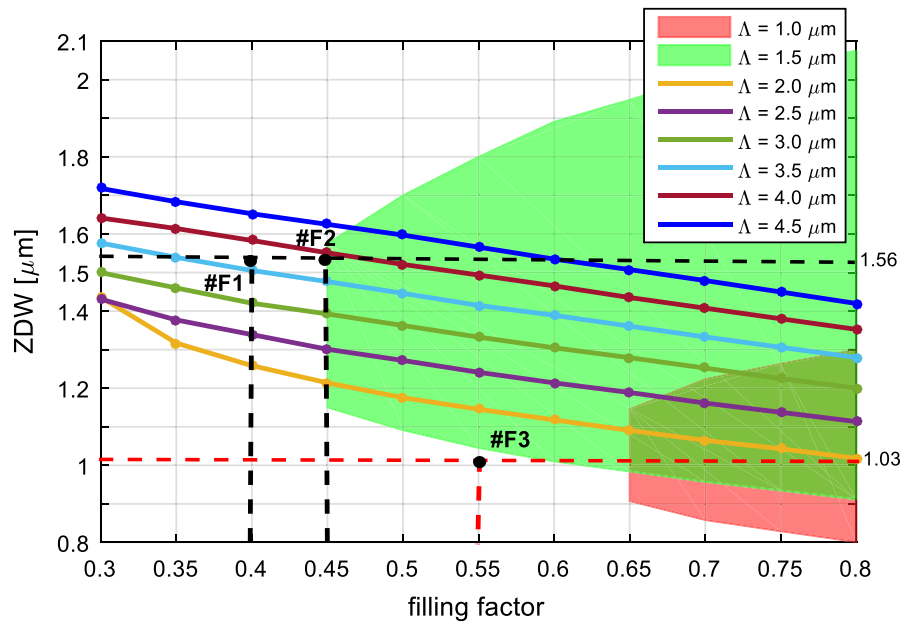

Fig. 4 The ZDW shifts with various lattices pitch $\Lambda$ and filling factors $f$

Table 2 The geometrical parameters for selected structures

\begin{tabular}{llll}
\hline Parameter & $\#_{1}$ & $\#_{2}$ & $\# F_{3}$ \\
\hline Lattice pitch $\Lambda(\mu \mathrm{m})$ & 1.5 & 4.0 & 1.5 \\
Filling factor $f=d / \Lambda$ & 0.4 & 0.45 & 0.55 \\
Cladding holes diameter $d(\mu \mathrm{m})$ & 0.6 & 1.8 & 0.825 \\
Tetrachloroethylene core diameter $\mathrm{D}_{\mathrm{c}}(\mu \mathrm{m})$ & 2.28 & 5.84 & 2.01 \\
\hline
\end{tabular}

$\mathrm{PCF}$ in the all normal dispersion regime at locations ' 2 ' and ' 3 ' in Fig. 3a, respectively. In this case, the maximum dispersion increases with increasing $f$ when $\Lambda$ is constant. Similar behavior can also be observed when increase the lattice pitch with the filling factor is constant. In addition, increasing the lattice pitch makes dispersion flatter ultimately becomes monotonous.

Figure 4 shows the ZDW shift with various $\Lambda$ and $f$. For a given $\Lambda$ value, ZDW is usually shifted toward the smaller wavelengths with the increase of filling factor $f$. Meanwhile, for a given $f$, the ZDW will be shifted toward longer wavelengths if increasing $\Lambda$. In particular, for the case of red area (corresponding with $\Lambda=1.0 \mu \mathrm{m}$ and $f$ changing from 0.65 to 0.8 ) and green area (corresponding with $\Lambda=1.5 \mu \mathrm{m}$ and $f$ changing from 0.45 to 0.8 ), the PCF has two ZDWs. In the rest cases, for the left of the red area, corresponding the fibers with $\Lambda=1.0 \mu \mathrm{m}$, it is fulfilled for $f$ from 0.3 to 0.6 and from 0.3 to 0.4 for fiber with $\Lambda=1.5 \mu \mathrm{m}$ left of the green area, the PCF with all normal dispersion have no ZDW.

The optimization criteria aiming at generations of SC at selected wavelengths $(1.03 \mu \mathrm{m}$ and $1.56 \mu \mathrm{m}$ ), include the flatness, indication of the dispersion characteristic, and the amount of difference between ZDW and pump wavelengths. On the basis of preliminary calculations, we proposed three PCFs, namely $\# \mathrm{~F}_{1}, \# \mathrm{~F}_{2}$ and $\# \mathrm{~F}_{3}$. The geometrical parameters of the fibers are introduced in Table 2. The first fiber $\left(\# \mathrm{~F}_{1}\right)$ is designed to work in the normal dispersion range with the pump wavelength of $1.56 \mu \mathrm{m}$. PCF with normal dispersions does not have any ZDW which, in Fig. 4, is in the left of the red area and left of the green area as described above. Although, fibers having $\Lambda=1.0 \mu \mathrm{m}$ (an example as ' 2 ' 
in Fig. 3a) have all normal dispersion with $f$ changing from 0.3 to 0.6 , but their dispersion curves are less flat than those of fibers with $\Lambda=1.5 \mu \mathrm{m}$ (see Fig. 3c). In addition, the broadest SC spectrum would be achieved by pumping near the local maximum of the dispersion curve. Therefore, PCF with parameters $\Lambda=1.5 \mu \mathrm{m}, f=0.4$ was selected as optimal (point $\# \mathrm{~F}_{1}$ in Fig. 4).

For fiber $\# \mathrm{~F}_{2}$ with parameters $\Lambda=4.0 \mu \mathrm{m}, f=0.45$ (point $\# \mathrm{~F}_{2}$ in Fig. 4), it is expected to generate the high coherent $\mathrm{SC}$ in the anomalous regime at the pump wavelength of $1.56 \mu \mathrm{m}$. This fiber was selected because it has ZDW at $1.55 \mu \mathrm{m}$ which is the closest one to the pumping wavelength. In addition, this fiber also has the flattest dispersion for all dispersion characteristic with $\Lambda=4.0 \mu \mathrm{m}$.

The fiber $\# \mathrm{~F}_{3}$ with parameters $\Lambda=1.5 \mu \mathrm{m}, f=0.55$ (point $\# \mathrm{~F}_{3}$ in Fig. 4), is expected to generate high coherent SC in the normal regime at the pump wavelength of $1.03 \mu \mathrm{m}$. The reason for this selection is that the fiber has the first ZDW at $1.04 \mu \mathrm{m}$, which is the closest wavelength compared to the one pumped. Another reason is that the dispersion at $1.03 \mu \mathrm{m}$ equals $-2.763 \mathrm{ps} / \mathrm{nm} / \mathrm{km}$, which is the closest value to the horizontal axis for all dispersion characteristic with $\Lambda=1.5 \mu \mathrm{m}$. This was beneficial to spectrally broaden, effectively suppress, and the noise seeded dynamics.

The properties of these three fiber structures are studied in detail. The material losses shown in Fig. 2 were incorporated in calculations. Figure 5 depicts the dispersion characteristics for these fibers. Fiber $\# \mathrm{~F}_{1}$ exhibits all-normal dispersion in the whole analyzed wavelength range and the dispersion at $1.56 \mu \mathrm{m}$ equals $-15 \mathrm{ps} / \mathrm{nm} / \mathrm{km}$, while fiber $\# \mathrm{~F}_{2}$ has ZDW at $1.55 \mu \mathrm{m}$ and the dispersion at the pump wavelength is equal to $3.20 \mathrm{ps} / \mathrm{nm} / \mathrm{km}$. In the rest case, fiber $\# \mathrm{~F}_{3}$ has first $\mathrm{ZDW}$ at $1.04 \mu \mathrm{m}$ and the dispersion at $1.03 \mu \mathrm{m}$ is equal to $-4.85 \mathrm{ps} / \mathrm{nm} / \mathrm{km}$.

The effective mode area and nonlinear coefficient of these structures are presented in Fig. 6. The nonlinear coefficient $\gamma$ is calculated by the equation $\gamma=n_{2} \omega_{0} / \mathrm{cA}$ eff, where $\omega_{0}$ is the central frequency of the pulse, $\mathrm{c}$ is the speed of light in the vacuum, and $\mathrm{A}_{\text {eff }}$ is the effective mode area for the fundamental mode of the fiber. The obtained results show that the mode area of the fundamental mode increases almost linearly with the wavelength. The effective mode area for the fundamental mode of fibers $\# F_{1}$ and $\# F_{2}$ are $4332 \mu \mathrm{m}^{2}$, and $16.670 \mu \mathrm{m}^{2}$ for a pump wavelength of $1.56 \mu \mathrm{m}$, while their nonlinear coefficient is $156.9 \mathrm{~W}^{-1} \mathrm{~km}^{-1}$ and $40.79 \mathrm{~W}^{-1} \mathrm{~km}^{-1}$, respectively. In the case of the

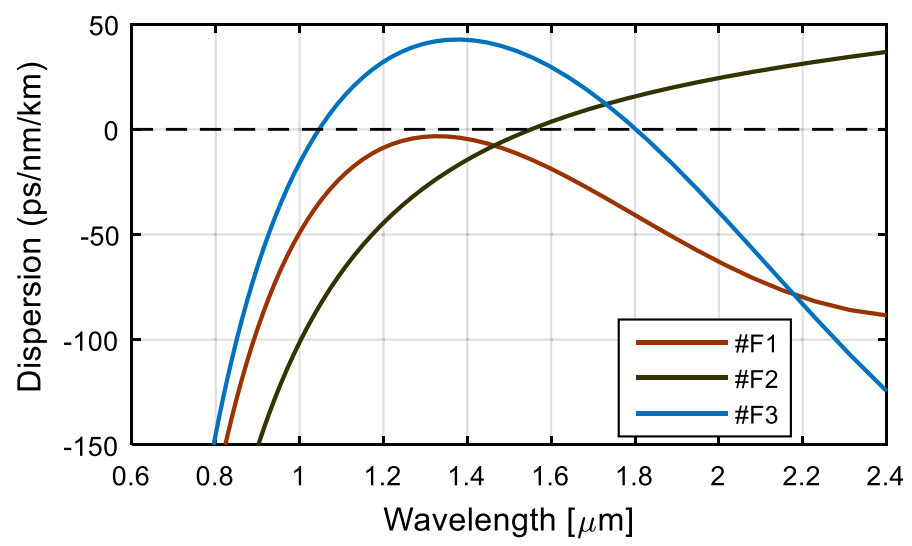

Fig. 5 Characteristics of the fundamental mode dispersion for the fiber $\# F_{1}, \# F_{2}$, and $\# F_{3}$ 


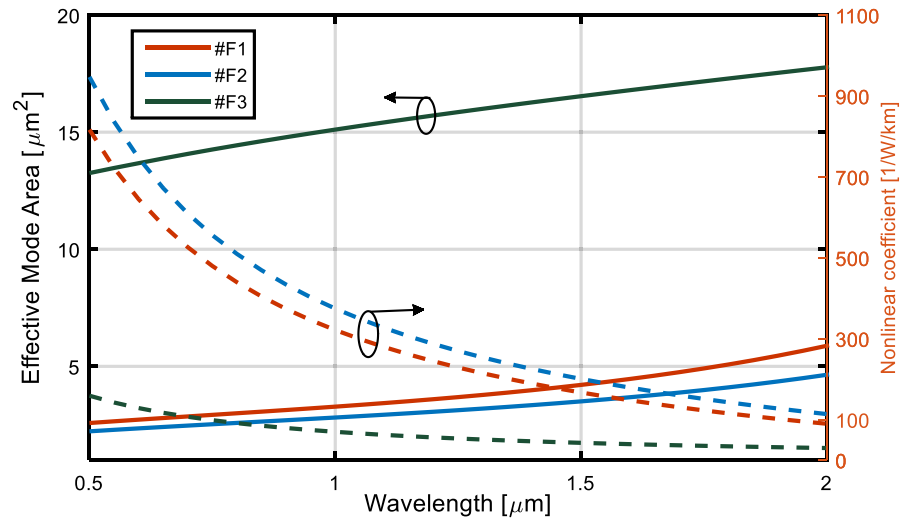

Fig. 6 The effective mode area and nonlinear coefficient of the proposed PCF. The solid lines and dashed lines denote for mode area and nonlinear coefficient, respectively

pump wavelength at $1.03 \mu \mathrm{m}$, the effective mode area of the fiber $\# \mathrm{~F}_{3}$ equals $3591 \mu \mathrm{m}^{2}$, while its nonlinear coefficient is $189.3 \mathrm{~W}^{-1} \mathrm{~km}^{-1}$.

Attenuation characteristics of the fundamental mode as a function of the wavelength for these three fibers are shown in Fig. 7. It is clear that the attenuation characteristics follow the bulk material losses of $\mathrm{C}_{2} \mathrm{Cl}_{4}$, playing the major role. The highest losses are observed for fiber $\# \mathrm{~F}_{2}$ because this fiber has the largest core. For the wavelength of $1.88 \mu \mathrm{m}$ the losses reach the highest values with $0.04 \mathrm{~dB} \mathrm{~cm}^{-1}, 0.042 \mathrm{~dB} \mathrm{~cm}^{-1}$, and $0.053 \mathrm{~dB} \cdot \mathrm{cm}^{-1}$ for $\# F_{1}, \# F_{3}$, and $\# F_{2}$, respectively.

For optimized fibers, we also verify whether the selected fiber was single mode or multimode at the pump wavelengths. The normalized frequency $V$ of fiber $\# \mathrm{~F}_{1}$ and fiber $\# \mathrm{~F}_{2}$ calculated at $1.56 \mu \mathrm{m}$ are around 2.24 and 2.49 , respectively, so the fiber $\# \mathrm{~F}_{1}$ is a single mode and fiber $\#_{2} \mathrm{~F}_{2}$ is multimode until this wavelength. Meanwhile, $V$ parameter of the fiber $\mathrm{HF}_{3}$ calculated at $1.03 \mu \mathrm{m}$ is 2.54 , which indicates this multimode behavior.

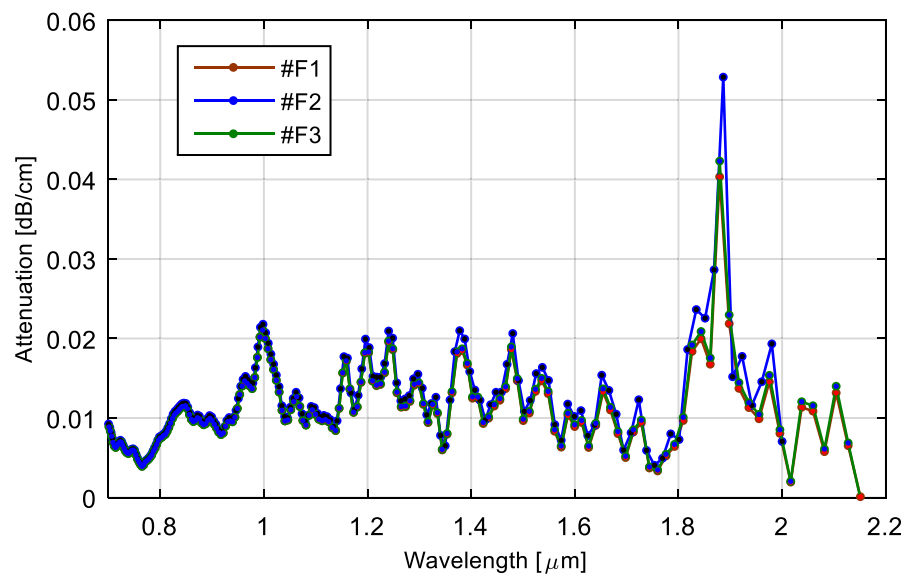

Fig. 7 Characteristics of attenuation of the fundamental mode for the fibers $\# F_{1}, \# F_{2}$ and $\# F_{3}$ 


\section{Supercontinuum generation in optimized structures}

The following discussions are dedicated to study on SC formation in those optimized structured fibers only for the fundamental mode. For this purpose, we solved the GNLSE with use of the split-step Fourier method (Agrawal 2000):

$$
\begin{aligned}
\partial_{z} \tilde{A}= & -\frac{\tilde{\alpha}(\omega)}{2} \tilde{A}+i \tilde{\beta}(\omega) \tilde{A} \\
& +i \frac{n_{2}\left(\omega_{0}\right) \omega}{c A_{\text {eff }}(\omega)} \tilde{A} \mathcal{F}\left[\int_{-\infty}^{\infty} R\left(t^{\prime}\right) \mid A\left(z,\left.\left(t-t^{\prime}\right)\right|^{2} d t^{\prime}\right]\right.
\end{aligned}
$$

where $\tilde{A}(\omega)$ is the frequency domain of an envelope pulse $\mathrm{A}(\mathrm{t})$. The influence of dispersion characteristics $\beta(\omega)$ on the nonlinear properties of the fiber is described by a product of the complex spectral envelope $\tilde{A}(\omega)$ and $\tilde{\beta}(\omega)=\beta(\omega)-\left(\omega-\omega_{0}\right) \beta_{1}-\beta_{0}$, where $\beta_{0}$ and $\beta_{1}$ are the dispersion coefficients associated with the Taylor series expansion of the propagation constant $\beta(\omega)$ about $\omega_{0}$. The term $\widetilde{\alpha}(\omega)$ is the frequency domain of the attenuation coefficient $\alpha(t)$. In simulations, the attenuation term is approximated by the sum of confinement loss and material loss, $n_{2}$ is the nonlinear refractive index of $\mathrm{C}_{2} \mathrm{Cl}_{4}$, while $A_{\text {eff }}(\omega)$ is the effective mode area.

The response function $R\left(t^{\prime}\right)$ depends on the contribution mechanism e.g. molecular reorientation, molecular interactions, collision-induced polarizability, electronic response, etc. It can be expressed as (Chemnit et al. 2018; Agrawal 2000):

$$
\begin{aligned}
R\left(t^{\prime}\right)= & {\left[2 n_{e l}+\left(n_{2 l} C_{2 l} e^{-\frac{t^{\prime}}{t_{f l}}} \int_{0}^{\infty} \frac{\sin \left(\omega t^{\prime}\right)}{\omega} g(\omega) d \omega+\sum_{k=c, d} n_{2 k} C_{2 k}\left(1-e^{-\frac{t^{\prime}}{t_{r k}}}\right) e^{-\frac{t^{\prime}}{t_{k k}}}\right) \Theta\left(t^{\prime}\right)\right.} \\
& \left.+n_{2, R} \operatorname{Im}\left(F^{-1}\{S(\omega)\}\right)\right] \frac{1}{N}
\end{aligned}
$$

where the subscripts $e l, d, l, c$ indicates the bound-electronic, molecular reorientation, molecular interaction and collision-induced, respectively, while the coefficients $C_{2 l, 2 d, 2 c}$ are normalized constant and $N=\left(n_{2 e l}+n_{2 c}+n_{2 d}+n_{2 l}\right) \cdot n_{2, R}$ is the Raman contribution and the term $g(\omega)$ stands for the distribution function of vibration motion.

The coherence properties of the generated supercontinuum in the proposed PCFs are performed. It considers the addition of one photon per mode noise with a random phase, and it is evaluated within the first-order degree of coherence (Zhao et al. 2018), given by:

$$
\left|g_{12}^{(1)}\left(\lambda, t_{1}-t_{2}=0\right)\right|=\left|\frac{E_{1}^{*}\left(\lambda, t_{1}\right) E_{2}\left(\lambda, t_{2}\right)}{\left[\left|E_{1}\left(\lambda, t_{1}\right)\right|^{2}\left|E_{2}\left(\lambda, t_{2}\right)\right|^{2}\right]^{1 / 2}}\right|
$$

Here we assumed that the pump pulse was Gaussian-shaped. The evolution of supercontinuum is simulated with various input pulse energy. The response function $R\left(t^{\prime}\right)$ parameters: $n_{2 e l}=5.5302 \times 10^{-20}\left(\mathrm{~m}^{2} / \mathrm{W}\right), \quad n_{2 d}=50.1 \times 10^{-20}\left(\mathrm{~m}^{2} / \mathrm{W}\right), \quad n_{2 l}=20.8 \times 10^{-20}$ $\left(\mathrm{m}^{2} / \mathrm{W}\right), n_{2 c}=3.1 \times 10^{-20}\left(\mathrm{~m}^{2} / \mathrm{W}\right), n_{2, R}=1.6 \times 10^{-20}\left(\mathrm{~m}^{2} / \mathrm{W}\right), \tau_{r, c}=0.1(\mathrm{ps}), \tau_{f, d}=4.5(\mathrm{ps})$, $\tau_{f, c}=0.00298(\mathrm{ps}), \tau_{r, d}=0.1(\mathrm{ps}), \tau_{f, l}=0.00298(\mathrm{ps}), \omega_{0}=4\left(\mathrm{ps}^{-1}\right), \sigma=6.3\left(\mathrm{ps}^{-1}\right)($ Chemnit 
et al. 2018). Results of the numerical simulations for the three considered structures are presented in Figs. 8, 9 and 10. They show numerically generated SC spectral, the calculated first-order complex degree of coherence of the generated SC pulses and the spectral evolution of the pulses along the fibers with along propagation.

The all-normal SC generation in $\# \mathrm{~F}_{1}$ was investigated with the input pulses having a central wavelength at $1.56 \mu \mathrm{m}$, pulse duration of $90 \mathrm{fs}$ and various energy pulses. With input pulse energy of $1.5 \mathrm{~nJ}$, spectral bandwidth covers from 0.8 to $2.0 \mu \mathrm{m}$ within $10 \mathrm{~dB}$ dynamic range. Figure $8 \mathrm{~b}$ depicts the evolution of the $\mathrm{SC}$ spectrum along fiber $\# \mathrm{~F}_{1}$, and temporal profile at various propagation lengths. At the beginning of propagation length, the spectral broadening is induced by a self-phase modulation (SPM), which is characterized by the temporal spectrogram in S-shape. Due to the effect of dispersion nonlinear, i.e. selfsteepening, the spectrum is asymmetry toward shorter wavelengths. The short wavelengths generated by SPM experience the high amount of normal dispersion and travel slower than the tail component at the center of the pulse. The overlap between the slower and tail components would generate the new wavelengths by four-wave mixing (FWM), which are
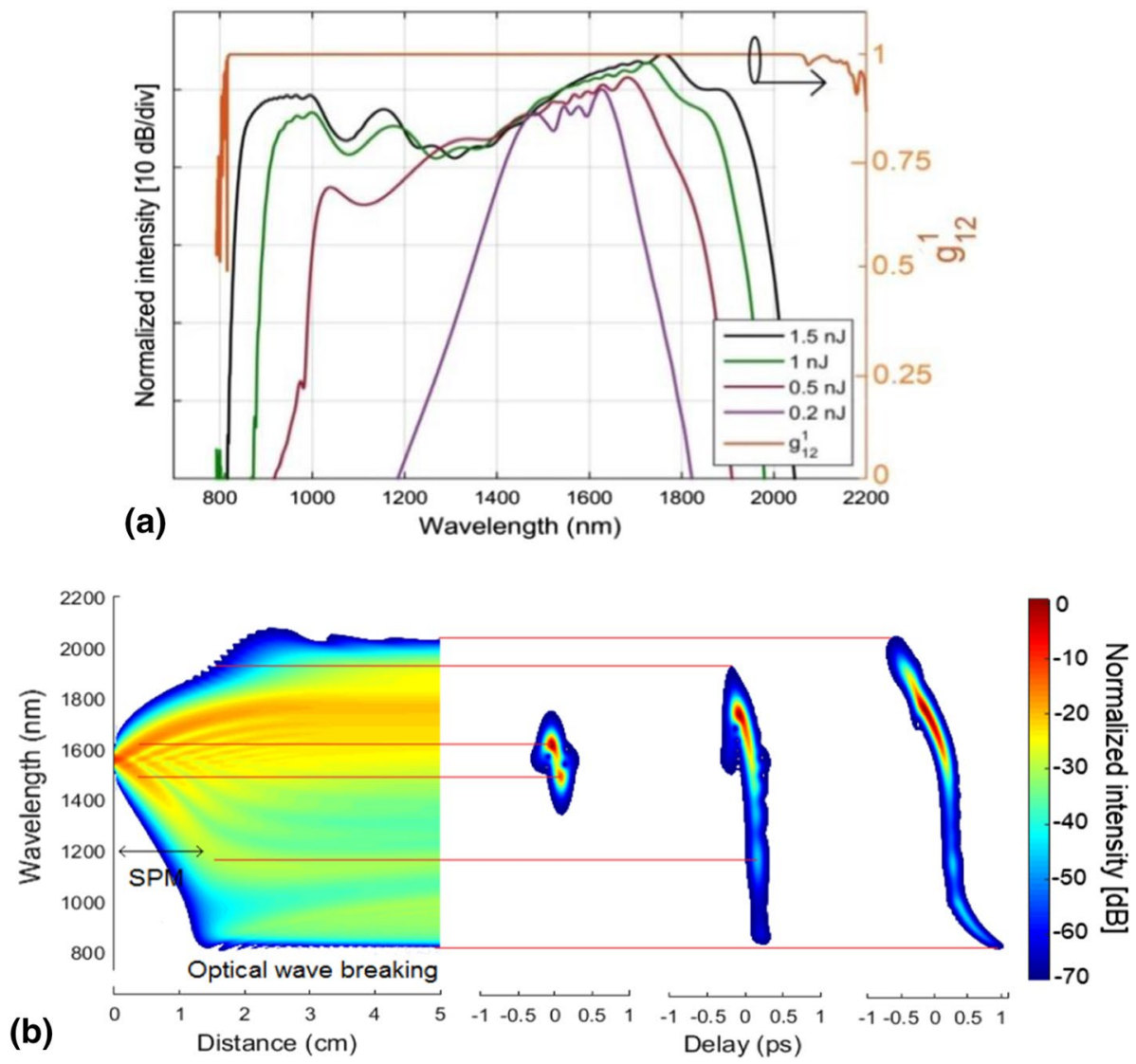

Fig. 8 SC spectrum: a for various input pulse energy in $5 \mathrm{~cm}$ length when pumped with pulses of $90 \mathrm{fs}$ duration, $1.56 \mu \mathrm{m}$ pump wavelength and the first-order coherence is calculated with 20 individual pairs with random single-photon-per-mode noise seed for $1.5 \mathrm{~nJ}$; b evolution of the SC along fiber and temporal profile at various propagation lengths, for $\# \mathrm{~F}_{1}$ 

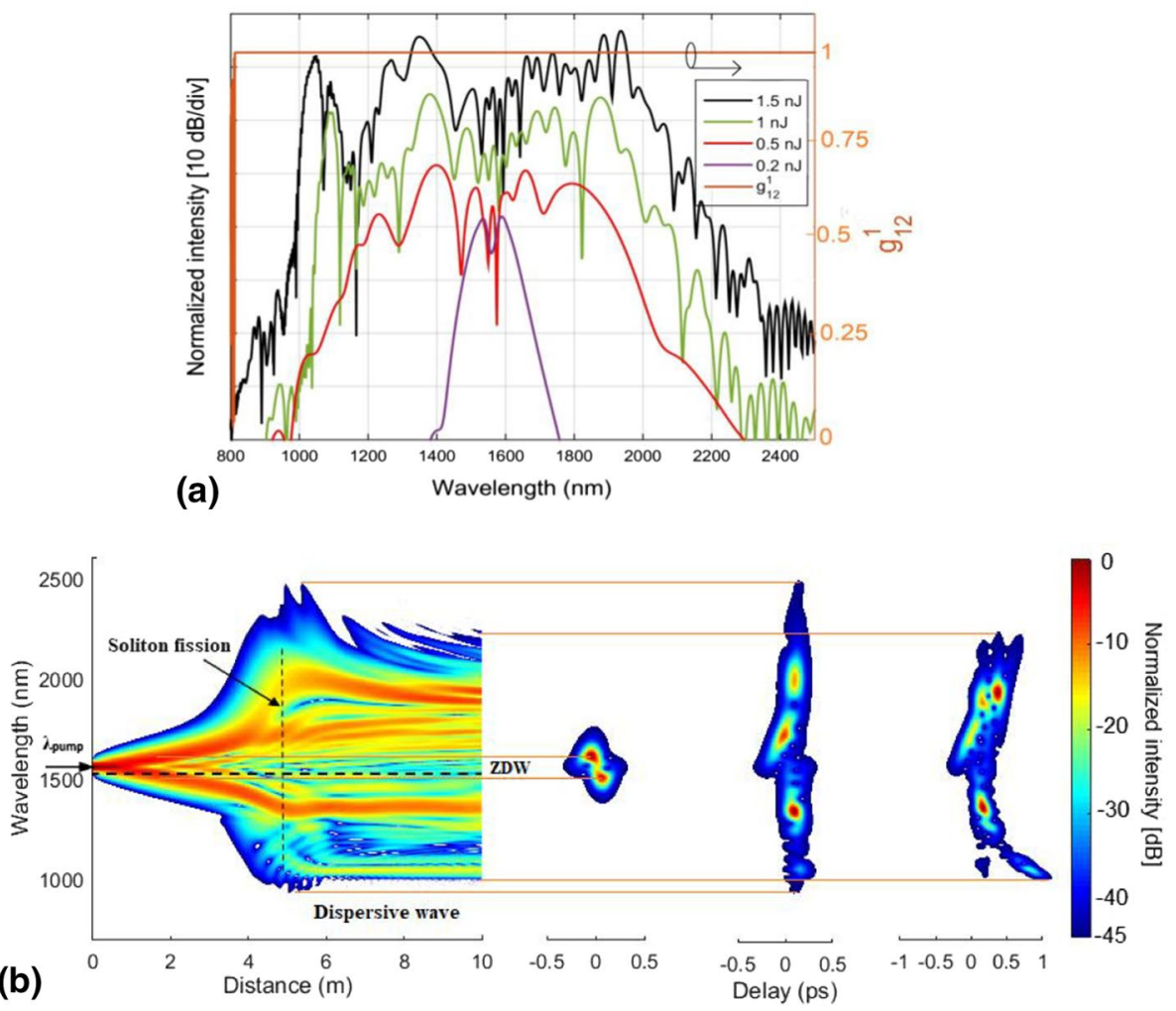

Fig. 9 SC spectrum: a for various input pulse energy in $10 \mathrm{~cm}$ length when pumped with pulses of $90 \mathrm{fs}$ duration, $1.56 \mu \mathrm{m}$ pump wavelength and the first-order coherence is calculated with 20 individual pairs with random single-photon-per-mode noise seed for $1.5 \mathrm{~nJ}$; b evolution of the SC along fiber and temporal profile at various propagation length, for $\mathrm{HF}_{2}$

attributed to optical wave breaking (OWB). As shown in Fig. 8b, OWB firstly occurs in the trailing edge of the pulse at $1.5 \mathrm{~cm}$ of propagation and generates the new wavelength band around $0.9 \mu \mathrm{m}$. On the leading edge, OWB occurs only after $2.5 \mathrm{~cm}$ of propagation and creates a new wavelength band around $2.0 \mu \mathrm{m}$. During further propagation, the spectral broadening at the trailing edge of the pulse is restricted by the high slope of the dispersion profile. At the leading edge of the pulse, the further broadening is also limited due to the large effective mode area, and thus low nonlinear coefficient at the long wavelength. As shown in Fig. 8b, the spectral broadening is completed around $2.5 \mathrm{~cm}$. For further propagation, the energy of the pulse is redistributed from the central area to the edges resulting in the further flat on the wings of the output spectrum and stretching out of group delay trace, as well.

The first-order degree of coherence is calculated with 20 individual pairs of the random noise seeds. Its value is approx. 1 over the spectrum (Fig. 8a). It means that the all-normal dispersion $\mathrm{SC}$ generation in $\mathrm{HF}_{1}$ has the potential for high temporal coherence.

In the case of the fiber $\# \mathrm{~F}_{2}$, the $\mathrm{SC}$ generation is analyzed with central wavelength of input pulse at $1.56 \mu \mathrm{m}$, and pulse duration of $90 \mathrm{fs}$. The pump wavelength at the anomalous dispersion regime, soliton dynamics, e.g. soliton fission, self-frequency shifting (Dudley 

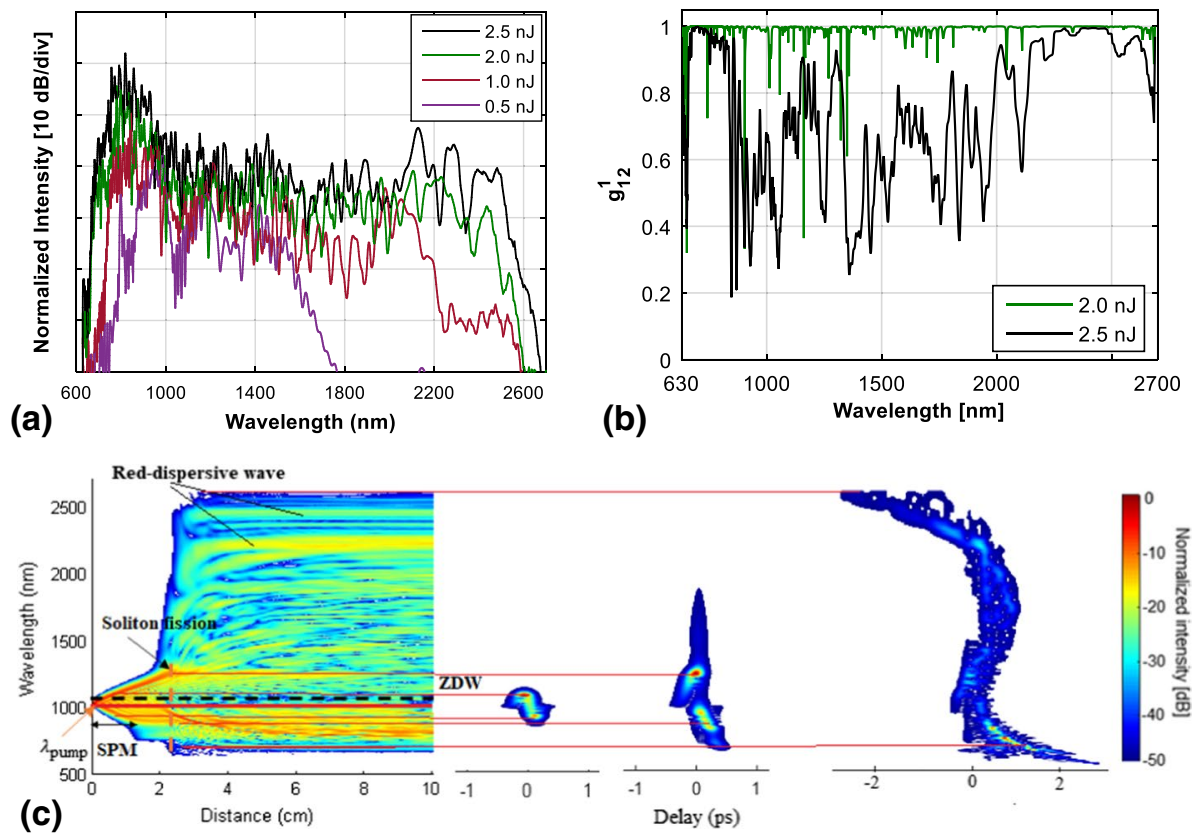

Fig. 10 SC spectrum: a for various input pulse energy in $10 \mathrm{~cm}$ length when pumped with pulses of $120 \mathrm{fs}$ duration, $1.03 \mu \mathrm{m}$ pump wavelength; $\mathbf{b}$ the first-order coherence is calculated with 20 individual pairs with random single-photon-per-mode noise seed for $2.0 \mathrm{~nJ}$ and $2.5 \mathrm{~nJ}$; c evolution of the SC along fiber and temporal profile at various propagation length for $2.0 \mathrm{~nJ}$, for $\mathrm{HF}_{3}$

et al. 2006) would play a significant role in spectral broadening. The input pulse transforms into higher-order solitons which can fall apart into a series of fundamental solitons (Zhang et al. 2006) due to a small perturbation, such as high-order dispersion, or stimulated Raman scattering (SRS). During further propagation, the solitons would shift toward the longer wavelengths due to soliton self-frequency shifts, causing a considerable spectral expansion toward the side of red light. For the spectral broadening across the ZDWs, the dispersive wave can play a significant role to generate the new wavelength band in the normal dispersion regime (Dudley et al. 2006).

The characteristic lengths of $\#_{2}$ fiber are calculated according to equation:

$$
L_{D}=\frac{t_{0}^{2}}{\left|\beta_{2}\right|}, \quad L_{N L}=\frac{1}{\gamma P_{0}}, \quad L_{f i s s}=\sqrt{\frac{t_{0}^{2}}{\left|\beta_{2}\right| \gamma P_{0}}},
$$

where $L_{D}, L_{N L}, L_{f i s s}$ define the dispersive, nonlinear, and soliton fission characteristic length scales, respectively. $P_{0}$ and $t_{0}$ are the peak power and the pulse duration of the input pulse. $\beta_{2}$ represents the group velocity dispersion at the central wavelength of the input laser pulse.

For the case of input pulse energy $1.5 \mathrm{~nJ}$, corresponding to $\mathrm{P}_{0}=16 \mathrm{~kW}$, at pump wavelength $1.56 \mu \mathrm{m}, \beta_{2}=-0.0041\left(\mathrm{ps}^{2} / \mathrm{m}\right)$ we obtain: $\mathrm{L}_{\mathrm{D}}=196(\mathrm{~cm}), \mathrm{L}_{\mathrm{NL}}=0.0015(\mathrm{~cm})$. The soliton fission length $\mathrm{L}_{\text {fiss }}=5 \mathrm{~cm}$, which is in agreement with data in Fig. $9 \mathrm{~b}$.

The spectral bandwidth of the SC spectrum extends from 1.0 to $2.0 \mu \mathrm{m}$ within $30 \mathrm{~dB}$ dynamics range (Fig. 9a). The evolution of the $\mathrm{SC}$ spectrum in $\mathrm{AF}_{2}$ is shown in Fig. 9b. At 
the beginning of the propagation, SPM is the main contribution factor to spectral broadening. Since pump wavelength $(1.56 \mu \mathrm{m})$ is near the ZDW $(1.55 \mu \mathrm{m})$, a fraction of the spectrum is induced by SPM across the ZDW and experiences in normal-dispersion regime before soliton fission occurs. Moreover, with the small value of dispersion $\left(\beta_{2}=-0.0041 \mathrm{ps}^{2} / \mathrm{m}\right)$, the characteristic length $5 \mathrm{~L}_{\mathrm{D}}$, over which the ejected solitons begin separating, is extremely larger than the length of fiber $(10 \mathrm{~cm})$.

The amplification of input noise caused by modulation instability can be reduced in the normal dispersion and near-zero anomalous dispersion regimes resulting in the improvement of the coherent characteristics. The complex degree of first-order coherence is calculated from 20 individual pairs of spectra generated with the random noise seed. Its value is approx. 1 over the spectrum as shown in Fig. 9a. It indicates that the SC spectrum is high coherence.

Fiber $\#_{3}$ has two ZDWs at $1.04 \mu \mathrm{m}\left(\lambda_{D 1}\right)$ and $1.82 \mu \mathrm{m}\left(\lambda_{D 2}\right)$; the pump wavelength is at normal dispersion regime and near the zero-dispersion wavelength $\lambda_{D 1}$. For the case of $2.0 \mathrm{~nJ}$ input pulse energy, the spectral bandwidth of the SC spectrum extends from 0.7 to $2.4 \mu \mathrm{m}$. At the beginning of propagation, the spectral broadening is induced by SPM with S-shape characteristics of temporal profile. After across $\lambda_{D 1}$, the spectrum broadens rapidly due to soliton dynamics, e.g. soliton fission. The red-dispersive wave appears at $2 \mathrm{~cm}$ of propagation when the spectrum across zero-dispersion wavelength $\lambda_{D 2}$ and create a spectrum at wavelengths around $2.4 \mu \mathrm{m}$ (detail in Fig. 10c). $\mathrm{C}_{2} \mathrm{Cl}_{4}$ has a majority contribution for the nonlinear response from the non-instantaneous mechanism, e.g. diffusive reorientation libration. This leads the spectral bandwidth induced by soliton dynamics to be reduced when compared to the one in a media with a purely instantaneous Kerr response. The high fraction of noninstantaneous nonlinear response also suppresses the effect of modulation instability on the SC generation of the anomalous dispersion regime (Maji and Chaudhuri 2014). Therefore, the $\mathrm{SC}$ spectrum in $\mathrm{AF}_{3}$ is high coherence with random single-photon-per-made noise (Fig. 10b). However, unfortunately, this still comes at a cost of the complex temporal structure of the pulse, as can be seen in Fig. 10a. Furthermore, the coherent of SC spectral will decrease when input peak power increasing. For the case of energy, when it is higher than $2.5 \mathrm{~nJ}$, the SC spectrum becomes low coherent since the modulation instability frequency components are not coherent with the pump and fission of each soliton occur randomly (as shown in Fig. 10b).

The comparison between the properties of proposed PCFs and some other liquid-filled core PCFs are presented in Table 3. All the cases, the refractive index of liquids has higher than for fused silica. The obtained results indicated that the proposed fibers can be achieved at the same level of bandwidth as previous works. However, unlike most of other liquid-filled PCFs (except for $\mathrm{C}_{6} \mathrm{H}_{5} \mathrm{NO}_{2}$-filled PCFs), fiber $\# \mathrm{~F}_{1}$ having all normal dispersion can support a singlemode at pump wavelength $(1.56 \mu \mathrm{m})$. It is worth mentioning that a single-mode fiber can offer the SC generation with further broad spectral bandwidth similarly/like in multimode fiber with the same input peak power. The reason for this phenomenon is that the single-mode fibers allow avoiding the interaction between the modes existing in the fiber, which would transfer light energy from fundamental mode into high-order modes resulting in the reduction of the spectral bandwidth of SC spectrum (Poletti and Horak 2009).

\section{Conclusion}

In this paper, we reported numerical studies on three optimum structures of PCFs made of fused silica with a tetrachloroethylene-filled core to obtain both all-normal and anomalous dispersion characteristics. Due to the modifications of their micro-structured 


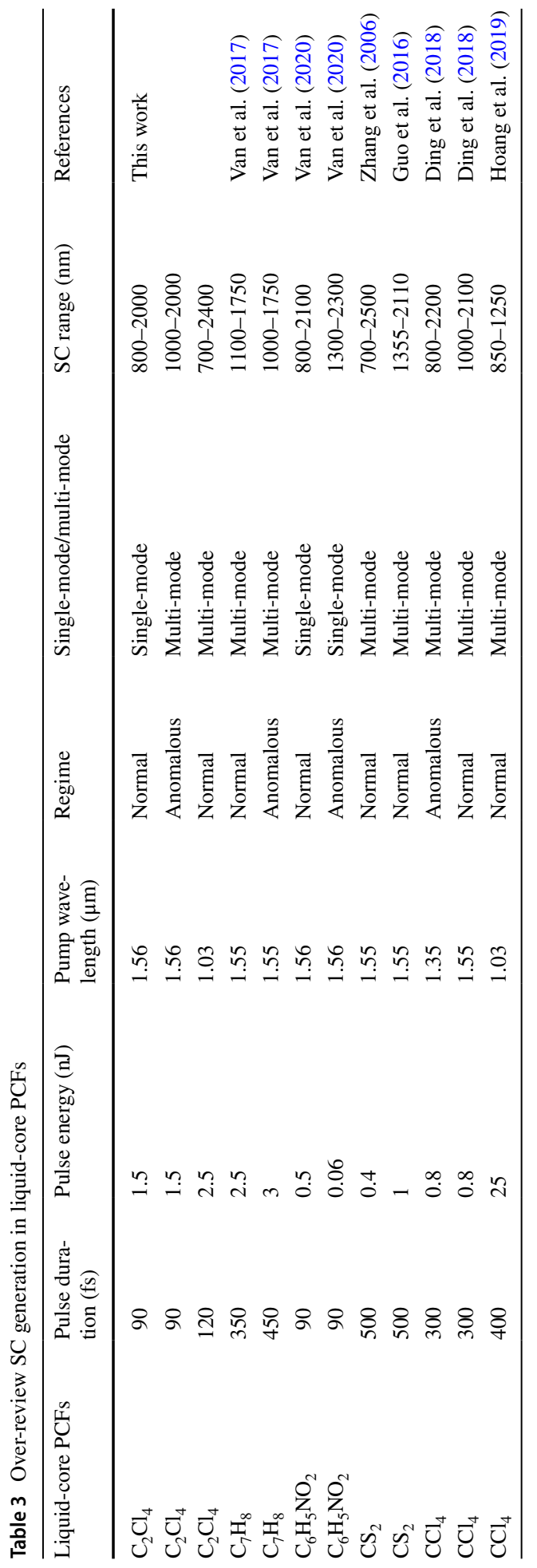


geometries, the large scope optimization process of the PCF structure has been carried out. This was done to achieve the flat dispersion, zero dispersion wavelength matched with a pump wavelength for broad SC spectrum. According to the conducted simulations, optimized fiber $\# \mathrm{~F}_{1}$ with lattice constant $\Lambda=1.5 \mu \mathrm{m}$ and filling factor $f=0.4$ exhibited an all-normal dispersion, and its peak equals $-15 \mathrm{ps} / \mathrm{nm} / \mathrm{km}$ at $1.56 \mu \mathrm{m}$. Fiber $\# \mathrm{~F}_{2}$ with $\Lambda=4.0 \mu \mathrm{m}$ and $f=0.45$ has anomalous dispersion for wavelengths longer than $1.55 \mu \mathrm{m}$, and the dispersion at $1.56 \mu \mathrm{m}$ is equal to $0.6 \mathrm{ps} / \mathrm{nm} / \mathrm{km}$. Fiber ${\# F_{3}}_{3}$ with $\Lambda=1.5 \mu \mathrm{m}, f=0.55$ has two zero dispersion wavelengths at $1.04 \mu \mathrm{m}$ and $1.82 \mu \mathrm{m}$. For this fiber, the dispersion at $1.03 \mu \mathrm{m}$ is equal to $-4.85 \mathrm{ps} / \mathrm{nm} / \mathrm{km}$.

Coherent, octave-spanning of the SC spectrum in $\# \mathrm{~F}_{1}$ was shown in the wavelength range of 0.8 to $2.0 \mu \mathrm{m}$ when the input pulse had a pump wavelength at $1.56 \mu \mathrm{m}, 90 \mathrm{fs}$ duration and $1.5 \mathrm{~nJ}$ pulse energy. Meanwhile, fiber $\mathrm{AF}_{2}$ could achieve a high coherence of the $\mathrm{SC}$ with pumped wavelength at an anomalous dispersion regime. The $\mathrm{SC}$ in $\# \mathrm{~F}_{2}$ induced by soliton dynamics and octave-spanning of the $\mathrm{SC}$ spectrum (from 1.0 to $2.0 \mu \mathrm{m})$ was generated with the same input pulse as fiber $\# \mathrm{~F}_{1}$. The last fiber $\left(\# \mathrm{~F}_{3}\right)$ demonstrated an over octave-spanning of the SC spectrum $(0.7 \div 2.4 \mu \mathrm{m})$ with the following initial pulse parameters: pump wavelength at $1.03 \mu \mathrm{m}$, and $120 \mathrm{fs}$ duration and $2.0 \mathrm{~nJ}$ pulse energy, which correspond to the peak power of $16.66 \mathrm{~kW}$.

Our optimized fibers have certain advantages over other types of optical fibers dedicated to SC. Due to the higher nonlinearity of $\mathrm{C}_{2} \mathrm{Cl}_{4}$ than that of fused silica, lower power of input pulses is required rather than in the case of silica PCFs (Van et al. 2018a; Ferhata et al. 2018). In comparison with other liquid-filled PCFs in previous works (Zhang et al. 2006; Ding et al. 2018; Van et al. 2020; Hoang et al. 2019; Van et al. 2017; Guo et al. 2016), fiber $\# F_{1}$ with an all-normal dispersion can offer a singlemode guidance at the pump wavelength, but this is not obtained in the cases of other liquids mentioned above, except for $\mathrm{C}_{6} \mathrm{H}_{5} \mathrm{NO}_{2}$-filled PCFs (Van et al. 2020). However, $\mathrm{C}_{6} \mathrm{H}_{5} \mathrm{NO}_{2}$-filled PCFs has relatively high attenuation in the near-IR range (Zhang et al. 2006). Meanwhile, fibers $\# F_{2}$ and $\# F_{3}$ are also multi-mode, which is the same as $\mathrm{C}_{7} \mathrm{H}_{8}, \mathrm{CCl}_{4}$ filled-core PCFs. Nevertheless, the attenuation of the fibers investigated in this work (around $0.02 \mathrm{~dB} / \mathrm{cm}$ ) is smaller than that of $\mathrm{C}_{7} \mathrm{H}_{8}$-filled (around $0.4 \mathrm{~dB}$ / $\mathrm{cm}$ ) (Van et al. 2017) and equivalent to $\mathrm{CCl}_{4}$-filled PCFs (around $0.0185 \mathrm{~dB} / \mathrm{cm}$ ) (Ding et al. 2018) at pump wavelengths. Another advantage of our fibers is that $\mathrm{C}_{2} \mathrm{Cl}_{4}$ is hightransparent from the visible to the mid-IR range $(0.5-3.39 \mu \mathrm{m})$ (Takahashi et al. 1985). Therefore, PCFs infiltrated with $\mathrm{C}_{2} \mathrm{Cl}_{4}$ can be used to generate SC in the mid-IR range, which has a significant role in biological imaging and optical coherent tomography (Holzwarth et al. 2000; Udem et al. 2002; Tu and Boppart 2013; Israelsen et al. 2019).

Acknowledgements This work was supported by Project TEAM TECH/2016-1/1 (POIR.04.04.0000-1C74/16) operated within the Foundation for Polish Science Team Programme co-financed by the European Regional Development Fund under Smart Growth Operational Programme (SG OP) and Priority Axis IV, National Science Centre Poland grant UMO-2016/21/M/ST2/00261.

Authors' contributions Not applicable.

Funding This work was supported by Project TEAM TECH/2016-1/1 (POIR.04.04.00-00-1C74/16) operated within the Foundation for Polish Science Team Programme co-financed by the European Regional Development Fund under Smart Growth Operational Programme (SG OP) and Priority Axis IV, National Science Centre Poland Grant UMO-2016/21/M/ST2/00261.

\section{Declarations}


Conflict of interest The authors declare no conflicts of interest.

Open Access This article is licensed under a Creative Commons Attribution 4.0 International License, which permits use, sharing, adaptation, distribution and reproduction in any medium or format, as long as you give appropriate credit to the original author(s) and the source, provide a link to the Creative Commons licence, and indicate if changes were made. The images or other third party material in this article are included in the article's Creative Commons licence, unless indicated otherwise in a credit line to the material. If material is not included in the article's Creative Commons licence and your intended use is not permitted by statutory regulation or exceeds the permitted use, you will need to obtain permission directly from the copyright holder. To view a copy of this licence, visit http://creativecommons.org/licenses/by/4.0/.

\section{References}

Agrawal, G.P.: Nonlinear Fiber Optics. Springer, Berlin (2000)

Ambrico, P.F., Amodeo, A., Girolamo, P.D., Spinelli, N.: Sensitivity analysis of differ ential absorption lidar measurements in the mid-infrared region. Appl. Opt. 39(36), 6847-6865 (2000)

Buczynski, R., Bookey, H.T., Pysz, D., Stepien, R., Kujawa, I., McCarthy, J.E., Waddie, A.J., Kar, A.K., Taghizadeh, M.R.: Supercontinuum generation up to $2.5 \mathrm{~mm}$ in photonic crystal fiber made of leadbismuth-galate glass. Laser Phys. Lett. 7, 666-672 (2010)

Challenor, J.: Toxicology of Solvents. Edited by Maeve McParland and Nicola Bates, Rapra Techn. Ltd (2002).

Chemnit, M., Gaida, C., Gebhardt, M., Stutzki, F., Kobelke, J., Tunnermann, A., Limpert, J., Schmidt, M.A.: Carbon chloride core fibers for soliton mediated supercontinuum generation. Opt. Express 26(3), 1094-4087 (2018)

Churin, D., Nguyen, T.N., Kieu, K., Norwood, R.A., Peyghambarian, N.: Mid-IR supercontinuum generation in an integrated liquid-core optical fiber filled with CS2. Opt. Mater. Express 3(9), 1358-1364 (2013)

Dai, S., Wang, Y., Peng, X., Zhang, P., Wang, X., Xu, Y.: A review of mid-infrared supercontinuum generation in chalcogenide glass fibers. Appl. Sci. 8(5), 707 (2018). https://doi.org/10.3390/app8050707

DHHS - Department of Health and Human Services. Agency for Toxic Substances and Disease Registry. Toxicological profile for tetrachloroethylene. https:/www.atsdr.cdc.gov/toxprofiles/tp18.pdf (1993).

Ding, Q.H., Pniewski, J., Van, H.L., Ramaniuk, A., Long, V.C., Borzycki, K., Xuan, K.D., Klimczak, M., Buczynski, R.: Optimization of optical properties of photonic crystal fibers infiltrated with carbon tetrachloride for supercontinuum generation with subnanojoule femtosecond pulses. Appl. Opt. 57(14), 3738-3746 (2018)

Du, F., Lu, Y.Q., Wu, S.T.: Electrically tunable liquid crystal photonic crystal fiber. Appl. Phys. Lett. 85, 2181-2183 (2004)

Dudley, J.M., Genty, G., Coen, S.: Supercontinuum generation in photonic crystal fiber. Rev. Mod. Phys. 78, 1135-1184 (2006)

Ebnali-Heidari, M., Dehghan, F., Saghaei, H., Koohi-Kamali, F., Moravvej-Farshi, M.K.: Dispersion engineering of photonic crystal fibers by means of fluidic infiltration. J. Mod. Opt. 59, 1384-1390 (2012)

Fanjoux, G., Margueron, S., Beugnot, J.C., Sylvestre, T.: Supercontinuum generation by stimulated RamanKerr scattering in a liquid-core optical fiber. J. Opt. Soc. Am. B. 34(8), 1677-1683 (2017)

Ferhata, M.L., Cherbi, L., Haddouche, I.: Supercontinuum generation in silica photonic crystal fiber at 1.3 $\mu \mathrm{m}$ and $1.65 \mu \mathrm{m}$ wavelengths for optical coherence tomography. Optik 152, 0030-4026 (2018)

Guo, B., Wang, Y., Peng, C., Zhang, H., Luo, G., Le, H., Gmachl, C., Sivco, D., Peabody, M., Cho, A.: Laser-based mid-infrared reflectance imaging of biological tissues. Opt. Express 12, 208-219 (2004)

Guo, Z., Yuan, J., Yu, C., Sang, X., Wang, K., Yan, B., Li, L., Kang, S., Kang, X.: Highly coherent supercontinuum generation in the normal dispersion liquid-core photonic crystal fiber. Progr. Electromagn. Res. M 48, 67-76 (2016)

Hoang, V.T., Kasztelanic, R., Anuszkiewicz, A., Stepniewski, G., Filipkowski, A., Ertman, S., Pysz, D., Wolinski, T., Khoa, D.X., Klimczak, M., Buczynski, R.: All-normal dispersion supercontinuum generation in photonic crystal fibers with large hollow cores infiltrated with toluene. Opt. Mater. Express. 8(11), 2159-3930 (2018)

Hoang, V.T., Kasztelanic, R., Filipkowski, A., Stepniewski, G., Pysz, D., Klimczak, M., Ertman, S., Van, C.L., Wolinski, T.R., Trippenbach, M., Khoa, D.X., Smietana, M.J., Buczynski, R.: Supercontinuum 
generation in an all-normal dispersion large core photonic crystal fiber infiltrated with carbon tetrachloride. Opt. Mater. Express 9(5), 2159-3930 (2019)

Holzwarth, R., Udem, T., Hänsch, W., Knight, J.C., Wadsworth, W.J., Russell, P.S.J.: Optical frequency synthesizer for precision spectroscopy. Phys. Rev. Lett. 85(11), 2264-2267 (2000)

IPCS - International Programme on Chemical Safety. Chloroform. http://www.inchem.org/documents/ehc/ ehc/ehc163.htm (1994).

Israelsen, N.M., Petersen, C.R., Barh, A., Jain, D., Jensen, M., Hannesschläger, G., Tidemand-Lichtenberg, P., Pedersen, C., Podoleanu, A., Bang, O.: Real-time high resolution mid-infrared optical coherence tomography. Light Sci. Appl. 8(11), 2047758 (2019). https://doi.org/10.1038/s41377-019-0122-5

Kabacinski, P., Kardas, T.M., Stepanenko, Y., Radzewicz, C.: Nonlinear refractive index measurement by SPM-induced phase regression. Opt. Express. 27(8), 11018-11028 (2019)

Kedenburg, S., Vieweg, M., Gissibl, T., Giessen, H.: Linear refractive index and absorption measurements of nonlinear optical liquids in the visible and near-infrared spectral region. Opt. Mater. Express. 2(11), 2159-3930 (2012)

Kedenburg, S., Steinmann, A., Hegenbarth, R., Steinle, T., Giessen, H.: Nonlinear refractive indices of nonlinear liquids: wavelength dependence and influence of retarded response. Appl. Phys. B 117, 803-816 (2014)

Klimczak, M., Michalik, D., Stepniewski, G., Karpate, T., Cimek, J., Forestier, X., Kasztelanic, R., Pysz, D., Stepien, R., Buczynski, R.: Coherent supercontinuum generation in tellurite glass regular lattice photonic crystal fibers. J. Opt. Soc. Am B 36(2), A112-A124 (2019)

Lanh, C.V., Hoang, V.T., Long, V.C., Borzycki, K., Xuan, K.D., Quoc, V.T., Trippenbach, M., Buczyński, R., Pniewski, J.: Optimization of optical properties of photonic crystal fibers infiltrated with chloroform for supercontinuum generation. Laser Phys. 29, 075107 (2019)

Liu, H., Yu, Y., Song, W., Jiang, Q., Pang, F.: Recent development of flat supercontinuum generation in specialty optical fibers. Opto-Electr. Adv. 2(2), 2096-2479 (2019)

Maji, P.S., Chaudhuri, P.R.: Supercontinuum generation in ultra-flat near zero dispersion PCF with selective liquid infiltration. Optik 125, 5986-5992 (2014)

Mode Solution. Lumerical Solutions, Inc. https://www.lumerical.com/tcad-products/mode/ (2020).

Nguyen, H.P.T., Tong, T.H., Saini, T.S., Luo, X., Suzuki, T., Ohishi, Y.: Highly coherent supercontinuum generation in a tellurite all-solid hybrid microstructured fiber pumped at 2 micron. Appl. Phys. Express. 12(4), 042010 (2019). https://doi.org/10.7567/1882-0786/ab0aac

Pniewski, J., Stefaniuk, T., Van, H.L., Long, V.C., Van, L.C., Kasztelanic, R., Stepniewski, G., Ramaniuk, A., Trippenbach, M., Buczynski, R.: Dispersion engineering in nonlinear soft glass photonic crystal fibers infiltrated with liquids. Appl. Opt. 55, 5033-5040 (2016)

Poletti, F., Horak, P.: Dynamics of femtosecond supercontinuum generation in multimode fibers. Opt. Express. 17, 6134-6147 (2009)

Raei, R., Ebnali-Heidari, M., Saghaei, H.: Supercontinuum generation in organic liquid-liquid core-cladding photonic crystal fiber in visible and near-infrared regions. J. Opt. Soc. Am. B 35(2), 0740-3224 (2018)

Sharma, U., Chang, E.W., Yun, H.S.: Long-wavelength optical coherence tomography at $1.7 \mu \mathrm{m}$ for enhanced imaging depth. Opt. Express. 16(24), 19712-19723 (2008).

Takahashi, H., Sugimoto, I., Takabayashi, T., Yoshida, S.: Optical transmission loss of liquid-core silica fibers in the infrared region. Opt. Commun. 53(3), 417-422 (1985)

Tan, C.Z.: Determination of refractive index of silica glass for infrared wavelengths by IR spectroscopy. J. Non-Cryst. Solids 223(1-2), 0022-3093 (1998)

Tu, H., Boppart, S.A.: Coherent fiber supercontinuum for biophotonic. Laser Photonics Rev. 7(5), 628-645 (2013)

Udem, T., Holzwarth, R., Hänsch, T.W.: Optical frequency metrology. Nature 416, 233-237 (2002)

Van, L.C., Anuszkiewicz, A., Ramaniuk, A., Kasztelanic, R., Xuan, K.D., Long, V.C., Trippenbach, M., Buczynski, R.: Supercontinuum generation in photonic crystal fibres with core filled with toluene. J. Opt. 19, 125604 (2017). https://doi.org/10.1088/2040-8986/aa96bc

Van, H.L., Long, V.C., Nguyen, H.T., Nguyen, A.M., Buczynski, R., Kasztelanic, R.: Application of ethanol infiltration for ultra-flatted normal dispersion in fused silica photonic crystal fibers. Laser. Phys. 28, 115106 (2018a). https://doi.org/10.1088/1555-6611/aad93a

Van, H.L., Buczynski, R., Long, V.C., Trippenbach, M., Borzycki, K., Nguyen, A.M., Kasztelanic, R.: Measurement of temperature and concentration influence on the dispersion of fused silica glass photonic crystal fiber infiltrated with water-ethanol mixture. Opt. Commun. 407, 417-422 (2018b)

Van, L.C., Hoang, V.T., Long, V.C., Borzycki, K., Xuan, K.D., Quoc, V.T., Trippenbach, M., Buczynski, R., Pniewski, J.: Supercontinuum generation in photonic crystal fibers infiltrated with nitrobenzene. Laser Phys. 30, 035105 (2020). https://doi.org/10.1088/1555-6611/ab6f09

Wohlfarth, C.: Refractive Indices of Pure Liquids and Binary Liquid Mixtures. Springer, Berlin (2008) 
Zhang, R., Teipel, J., Giessen, H.: Theoretical design of a liquid-core photonic crystal fiber for supercontinuum generation. Opt. Express. 14(15), 6800-6812 (2006)

Zhao, P., Reichert, M., Davit, S., Hagan, J., Stryland, E.: Temporal and polarization dependence of the nonlinear optical response of solvents. Optica 5(5), 2334-2536 (2018)

Publisher's Note Springer Nature remains neutral with regard to jurisdictional claims in published maps and institutional affiliations. 